Article

\title{
Beverage Consumption and Ulcerative Colitis: A Case-Control Study from Saudi Arabia
}

\author{
Anas Almofarreh ${ }^{1,2}$, Haytham A. Sheerah ${ }^{3,4,5, *}$, Ahmed Arafa $\left.{ }^{4,6}{ }^{(}\right)$, Shaik Shaffi Ahamed ${ }^{7}\left(\mathbb{D}\right.$, Osama Alzeer ${ }^{3,8}$, \\ Weiam Al-Hunaishi ${ }^{1}{ }^{\mathbb{D}}$, Mohamed Ma Mhimed ${ }^{9,10,11}$, Ali Al-Hazmi ${ }^{3,7}$ and Sin How Lim ${ }^{1,12}$
}

check for updates

Citation: Almofarreh, A.; Sheerah, H.A.; Arafa, A.; Ahamed, S.S.; Alzeer, O.; Al-Hunaishi, W.; Mhimed, M.M.; Al-Hazmi, A.; Lim, S.H. Beverage Consumption and Ulcerative Colitis: A Case-Control Study from Saudi Arabia. Int. J. Environ. Res. Public Health 2022, 19, 2287. https:// doi.org/10.3390/ijerph19042287

Academic Editors: Peter C. Konturek and Paul B. Tchounwou

Received: 1 December 2021 Accepted: 11 February 2022 Published: 17 February 2022

Publisher's Note: MDPI stays neutral with regard to jurisdictional claims in published maps and institutional affiliations.

Copyright: (C) 2022 by the authors. Licensee MDPI, Basel, Switzerland. This article is an open access article distributed under the terms and conditions of the Creative Commons Attribution (CC BY) license (https:// creativecommons.org/licenses/by/ $4.0 /)$.
1 Department of Social and Preventive Medicine, Faculty of Medicine, University of Malaya, Kuala Lumpur 50603, Malaysia; aalmofarreh@moh.gov.sa (A.A.); waam59@hotmail.com (W.A.-H.); howie.ceria@gmail.com (S.H.L.)

2 Ministry of Health, Riyadh 15595, Saudi Arabia

3 Health Promotion and Health Education Research Chair, King Saud University, Riyadh 11451, Saudi Arabia; oalzeer@hotmail.com (O.A.); aalhazmii@ksu.edu.sa (A.A.-H.)

4 Public Health, Department of Social Medicine, Graduate School of Medicine, Osaka University, Suita 565-0871, Japan; ahmed011172@med.bsu.edu.eg

5 Department of Preventive Cardiology, National Cerebral and Cardiovascular Center, Suita 564-8565, Japan

6 Department of Public Health, Faculty of Medicine, Beni-Suef University, Beni-Suef 62521, Egypt

7 Department of Family and Community Medicine, College of Medicine, King Saud University, Riyadh 11451, Saudi Arabia; sshaik@ksu.edu.sa

8 Department of Clinical Nutrition, King Khalid University Hospital, King Saud University, Riyadh 11451, Saudi Arabia

9 Cell and Tissue Culture Department, Libyan Center for Biotechnology Research, Tripoli 30313, Libya; mkhalifa2020@yahoo.com

10 Head of Information, Research and Data Analysis Department, National Center for Disease Control (NCDC)_Aljafara Branch, Tripoli 71171, Libya

11 Scientific Research Unit, Research and Development Department, Primary Health Care Institute, Tripoli 00218, Libya

12 Centre of Excellence for Research in AIDS (CERiA), Faculty of Medicine, University of Malaya, Kuala Lumpur 50603, Malaysia

* Correspondence: haytham@pbhel.med.osaka-u.ac.jp

Abstract: Background: The association between beverage intake and ulcerative colitis (UC) is not well-established, with no available data from Arab countries. Herein, we investigated the potential association of consuming coffee, tea, and carbonated soft drinks with UC among a population from Saudi Arabia. Methods: This hospital-based case-control study used data of 171 newly diagnosed UC patients and 400 patients with other gastrointestinal conditions who served as controls. All UC cases were ascertained by endoscopy, while beverage intake was assessed by a questionnaire that was completed before diagnosis. We computed odds ratios (ORs) and 95\% confidence intervals (95\% CIs) of UC and UC extension for frequent versus infrequent intakes of coffee, tea, and carbonated soft drinks using logistic regression. Results: Overall, 23.4\% of UC patients had pancolitis, 21.1\% extensive, $51.4 \%$ left-sided, and $4.1 \%$ proctitis. UC patients had a similar sex distribution to the controls but were older and had a lower BMI. After adjustment for age, sex, body mass index, and smoking history, frequent intakes of coffee and tea were associated with lower odds of UC: 0.62 (0.42, $0.91)$ and $0.53(0.35,0.79)$, respectively. On the other hand, frequent intakes of carbonated soft drinks were associated with increased odds of UC: $9.82(6.12,15.76)$. The frequency of beverage consumption was not associated with UC extension. Conclusion: UC was negatively associated with frequent coffee and tea consumption but positively associated with frequent carbonated soft drink intake in Saudi people. More population-based prospective cohort studies are needed to confirm our findings.

Keywords: ulcerative colitis; tea; coffee; carbonated soft drinks; case-control study; Saudi Arabia 


\section{Introduction}

Ulcerative colitis (UC) is a chronic inflammatory disease starting in the rectum and extending to proximal segments of the colon [1,2]. It is clinically characterized by frequent relapses of bloody diarrhea, abdominal pain, and bloating [1,2] that lead to poor quality of life and heavy financial burden $[3,4]$. The incidence and prevalence of UC have been increasing steadily over the past decades worldwide [5].

The real etiology of UC is still unknown; however, several genetic, environmental, and nutritional risk factors have been indicated, such as family history of UC, smoking, and some medications, including hormone replacement therapy, oral contraceptives, and nonsteroidal anti-inflammatory drugs [1]. Among these factors, a growing body of evidence, however inconclusive, has suggested that beverage consumption, namely coffee, tea, and soft drinks, could be related to UC risk [6]. However, the epidemiological studies reporting this evidence were performed in Western and East-Asian communities and had inconsistent findings [7-13]. In addition, the association between beverage consumption and UC extension has never been studied.

Saudi Arabia is among the largest countries in the East Mediterranean Region and is showing an increasing incidence of UC $[14,15]$. The Saudi population has unique dietary behaviors that are significantly different from those of Western and East-Asian populations. For example, the literature has shown a high prevalence of beverage consumption among Saudi people [16-18].

We therefore conducted this case-control study using data of newly diagnosed UC patients from a large polyclinic in Saudi Arabia to investigate the possible relationship between the intakes of coffee, tea, and carbonated soft drinks and UC or UC extension. We aspired that the results of this study could give us a better understanding of the nutritional risk factors for UC among Saudi patients.

\section{Methods}

\subsection{Study Population and Setting}

This hospital-based case-control study used secondary data of 171 patients with UC and 400 patients with other gastrointestinal conditions who were diagnosed between January 2009 and December 2017 in one private polyclinic in Riyadh, the Capital of Saudi Arabia. Our eligibility criteria for UC patients included (1) newly diagnosed patients, (2) UC diagnosis was ascertained by lower endoscopy with biopsies, (3) >18 years, (4) Saudi citizens, and (5) agreed to participate in the study by giving informed consent. Patients who served as controls had no confirmed or suspected inflammatory bowel disease, malignancy, diverticulosis, or polyposis based on their manifestations and laboratory findings.

\subsection{Ulcerative Colitis Diagnosis}

All patients with UC manifestations, such as abdominal pain, diarrhea, bloating, loss of appetite, unexplained weight loss, or bloody stool, had laboratory investigations, including urine and stool analysis for biomarkers of inflammation and serum complete blood count, C-reactive protein, erythrocyte sedimentation rates, bilirubin, alanine aminotransferase, creatinine, and alkaline phosphatase. Patients with probable UC manifestations and laboratory findings had lower gastrointestinal endoscopy with high-definition endoscopes utilizing either Olympus, Pentax, or Fujinon video scopes, and their biopsies were assessed histopathologically.

\subsection{Beverage Intake Assessment}

The intakes of coffee, tea, carbonated soft drinks, and alcohol were assessed during the first visit, before undergoing any laboratory or endoscopic intervention, using a selfadministered questionnaire. The questions on beverage intakes were as follows: "How frequently do you drink coffee?", "How frequently do you drink tea?", "How frequently do you drink carbonated soft drinks?", and "How frequently do you drink alcohol?". The available responses were "never or rarely", "once/week", "twice/week", and "daily". Tea included all 
kinds of tea, such as black and green tea, while carbonated soft drinks included sweetened and non-sweetened carbonated soft drinks.

\subsection{Covariates}

Age (years), sex (men or women), weight in $\mathrm{kg}$, and height in $\mathrm{cm}$, body mass index (BMI; calculated by weight in $\mathrm{kg}$ /height in $\mathrm{m}^{2}$ ), history of smoking (yes or no), and medical history of cardiovascular diseases (yes or no) and neurological disorders (yes or no) were assessed by the same baseline questionnaire. Illiterate participants sought help from investigators.

\subsection{Statistical Analyses}

The Chi-squared test and $t$-test were used to detect the differences in proportions (sex and smoking history) and mean values (age and BMI) between cases and controls. To obtain statistical power, the responses "never or rarely", "once/week", "twice/week" were merged into one category "infrequent", while the daily intake was considered "frequent". Since only three subjects reported alcohol intake, this question was omitted. The odds ratios (ORs) with their $95 \%$ confidence intervals (95\% CIs) of UC versus controls for frequent versus infrequent intakes of coffee, tea, and carbonated soft drinks were calculated separately by logistic regression. Three regression models were presented: model I: unadjusted, model II: adjusted for age and sex, and model III: adjusted for age, sex, BMI, and smoking history. Since all UC patients and controls had a negative history of cardiovascular and neurological diseases, these variables were not included in the regression models. Then, we calculated using the same regression models the ORs (95\% CIs) of severe forms of UC (pancolitis and extensive) versus other forms of UC (left-sided and proctitis) for frequent versus infrequent intakes of coffee, tea, and carbonated soft drinks. Data were analyzed using the Statistical Package for Social Science (SPSS) released in 2013 (IBM SPSS Statistics for Windows, Version 22.0, IBM Corporation, Armonk, New York, NY, USA).

\section{Results}

Patients with UC were older than their controls $(40.0 \pm 12.5$ versus $37.7 \pm 8.8$ years, $p$-value $=0.014)$, with a lower BMI $\left(25.3 \pm 5.8\right.$ versus $27.4 \pm 9.3 \mathrm{~kg} / \mathrm{m}^{2} ; p$-value $\left.=0.007\right)$ and proportion of ever-smoking history $(10.5 \%$ versus $20.5 \%$; $p$-value $=0.004)$. Sex distribution did not differ significantly between UC patients and the controls (men: 59.6\% versus 64.2\%; $p$-value $=0.300)($ Table 1$)$.

Table 1. Comparison between ulcerative colitis patients and their controls.

\begin{tabular}{|c|c|c|c|c|}
\hline \multicolumn{2}{|c|}{ Characteristics } & Ulcerative Colitis & Controls & $p$-Value \\
\hline \multicolumn{2}{|c|}{ Frequency } & 171 & 400 & - \\
\hline \multicolumn{2}{|c|}{ Age $($ mean $\pm S d)$, years } & $40.0 \pm 12.5$ & $37.7 \pm 8.8$ & 0.014 \\
\hline \multirow{2}{*}{ Sex, \% } & Men & 59.6 & 64.2 & \multirow{2}{*}{0.300} \\
\hline & Women & 40.4 & 35.8 & \\
\hline \multicolumn{2}{|c|}{ Body mass index (mean $\pm \mathrm{Sd}), \mathrm{kg} / \mathrm{m}^{2}$} & $25.3 \pm 5.8$ & $27.4 \pm 9.3$ & 0.007 \\
\hline \multicolumn{2}{|c|}{ Smoking, \% } & 10.5 & 20.5 & 0.004 \\
\hline
\end{tabular}

Frequent intakes of coffee and tea were respectively associated with lower odds of UC in the unadjusted model, $0.59(0.41,0.85)$ and $0.50(0.34,0.72)$; the age- and sex-adjusted model, $0.56(0.39,0.81)$ and $0.48(0.32,0.71)$; and after further adjustment for BMI and smoking, $0.62(0.42,0.91)$ and $0.53(0.35,0.79)$. On the other hand, frequent intakes of carbonated soft drinks were associated with increased odds of UC in the unadjusted model, $5.28(3.59,7.77)$, age-and sex-adjusted model, $8.34(5.33,13.06)$, and after further adjustment for BMI and smoking, $9.82(6.12,15.76)$ (Table 2). 
Table 2. Odds ratios and 95\% confidence intervals for ulcerative colitis according to beverage consumption.

\begin{tabular}{|c|c|c|}
\hline & Infrequent & Frequent \\
\hline \multicolumn{3}{|l|}{ Coffee } \\
\hline Ulcerative colitis, \% & 58.5 & 41.5 \\
\hline Controls, $\%$ & 45.5 & 54.5 \\
\hline Model I & 1 & $0.59(0.41,0.85)$ \\
\hline Model II & 1 & $0.56(0.39,0.81)$ \\
\hline Model III & 1 & $0.62(0.42,0.91)$ \\
\hline \multicolumn{3}{|l|}{ Tea } \\
\hline Ulcerative colitis, \% & 68.4 & 31.6 \\
\hline Controls, \% & 51.7 & 48.3 \\
\hline Model I & 1 & $0.50(0.34,0.72)$ \\
\hline Model II & 1 & $0.48(0.32,0.71)$ \\
\hline Model III & 1 & $0.53(0.35,0.79)$ \\
\hline \multicolumn{3}{|c|}{ Carbonated soft drinks } \\
\hline Ulcerative colitis, \% & 36.8 & 63.2 \\
\hline Controls, \% & 75.5 & 24.5 \\
\hline Model I & 1 & $5.28(3.59,7.77)$ \\
\hline Model II & 1 & $8.34(5.33,13.06)$ \\
\hline Model III & 1 & $9.82(6.12,15.76)$ \\
\hline
\end{tabular}

Model I: Unadjusted; Model II: Adjusted for age and sex; Model III: Adjusted for age, sex, body mass index, and history of smoking.

Endoscopy showed that $23.4 \%$ of UC patients had pancolitis, $21.1 \%$ extensive, $51.4 \%$ left-sided, and $4.1 \%$ proctitis (Figure 1). Frequent intakes of coffee, tea, and carbonated soft drinks were not associated with the extent of UC in the multivariable-adjusted models (Table 3).

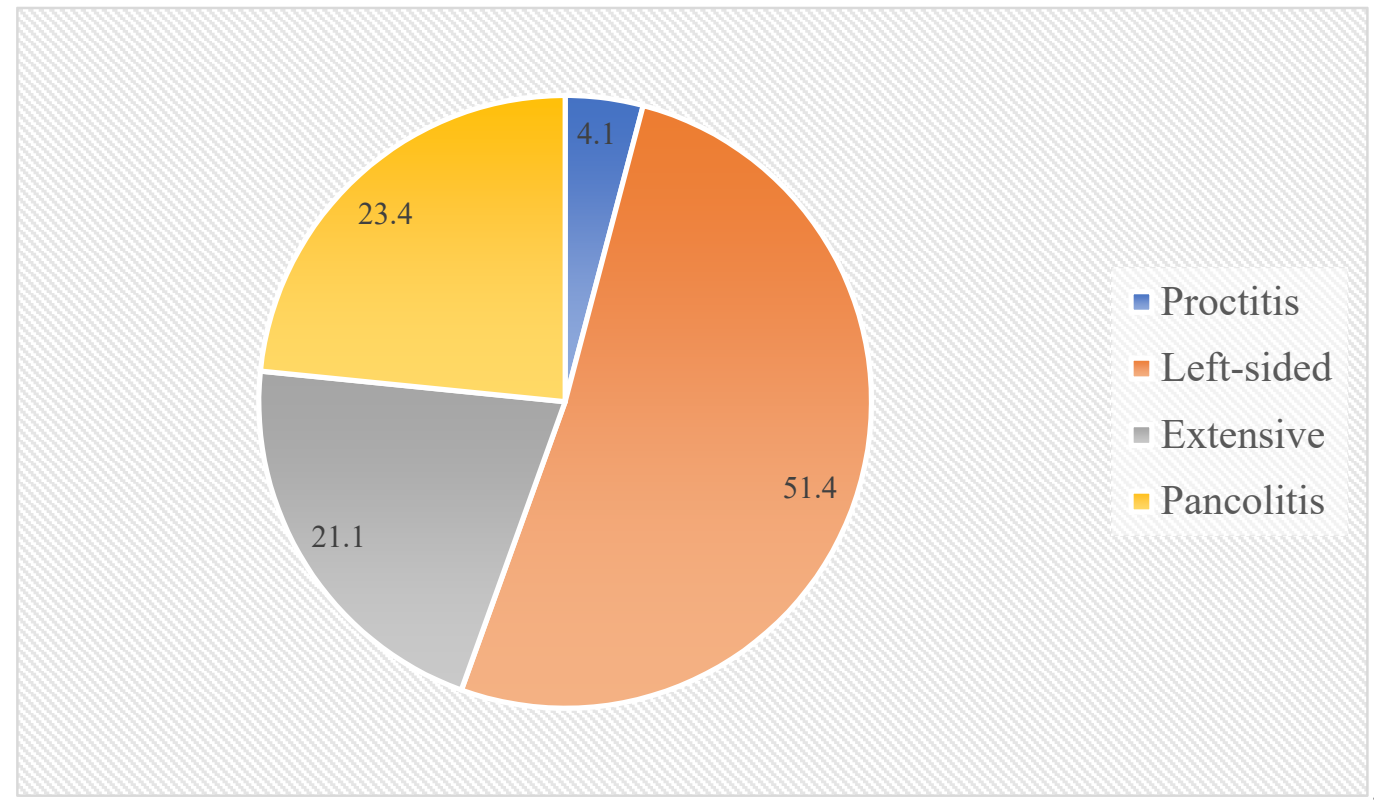

Figure 1. Extent of ulcerative colitis as detected by endoscopy. 
Table 3. Odds ratios and $95 \%$ confidence intervals for pancolitis according to beverage consumption.

\begin{tabular}{ccc}
\hline & Infrequent & Frequent \\
\hline Coffee & \\
\hline Extensive, $\%$ & 51.3 & 48.7 \\
\hline Mild to moderate, $\%$ & 64.2 & 35.8 \\
\hline Model I & 1 & $1.70(0.92,3.15)$ \\
\hline Model III & 1 & $1.31(0.70,2.45)$ \\
\hline Extensive, $\%$ & 1 & $1.68(0.88,3.19)$ \\
\hline Mild to moderate, $\%$ & Tea & 40.8 \\
\hline Model I & 59.2 & 24.2 \\
\hline Model II & 75.8 & $2.16(1.12,4.15)$ \\
\hline Model III & 1 & $2.18(1.09,4.35)$ \\
\hline Extensive, $\%$ & 1 & $2.00(0.95,4.19)$ \\
\hline Mild to moderate, $\%$ & 1 & 67.1 \\
\hline Model I & Carbonated soft drinks & 60.0 \\
\hline Model II & 32.9 & $1.36(0.72,2.56)$ \\
\hline Model III & 40.0 & $1.25(0.62,2.50)$ \\
\hline & 1 & $1.09(0.53,2.25)$ \\
\hline
\end{tabular}

Model I: Unadjusted; Model II: Adjusted for age and sex; Model III: Adjusted for age, sex, body mass index, and history of smoking.

\section{Discussion}

To the best of our knowledge, this is the first study to investigate the association between beverage intakes and UC among an Arab population. This study indicated that frequent coffee and tea consumption could be associated with lower odds of UC, while frequent intake of carbonated soft drinks could be associated with higher odds of UC. The frequency of beverage consumption was not associated with UC extension.

Our results were in line with previous studies. A case-control study including populations from eight Pacific-Asian countries and Australia showed that daily coffee and tea consumption versus none could be protective against $\mathrm{UC}(0.49(0.35,0.69)$ and $0.63(0.47$, $0.85)$, respectively), while consuming soft drinks $\geq$ two times/week versus none tended to be associated with increased UC $(1.55(0.83,2.90))$ [11]. A population-based case-control study from Sweden showed that drinking $\geq$ three cups of coffee/day compared with none was associated with a lower prevalence of UC: $0.3(0.2,0.5)$ [8]. Another population-based case-control study from the Netherlands showed higher odds of UC among those who reported drinking Cola more than once/week compared with none: $1.6(1.1,2.3)$ [10]. A meta-analysis of 16 studies detected inverse associations between drinking coffee, $0.58(0.33$, $1.05)$, and tea, $0.69(0.58,0.83)$, with UC risk, while soft drink consumption was positively associated with UC risk, $1.69(1.24,2.30)[6]$.

Biologically, the protective effects of coffee and tea against UC risk are not unexpected, since oral caffeine administration was shown to ameliorate acute colitis via downregulating Chitinase 3-like 1 expression, a host protein known to facilitate bacterial attachment to intestinal epithelial cells to trigger UC [19]. Tea polyphenols enhanced antioxidant levels and attenuate inflammation in animal models with colitis [20]. On the other hand, sugar intake in a previous prospective study increased the risk of UC [9]. Sugar intake can alter gut microbiota associated with UC. Furthermore, carbonated soft drinks are usually associated with fast food and the Western diet, which are considered risk factors for UC [21]. 
Investigating the distribution of UC extension is beyond the aim of this study; however, we noticed that $44.5 \%$ of our UC patients presented with severe forms: $23.4 \%$ with pancolitis and $21.1 \%$ with extensive UC. This is higher than previous studies, which put the maximum prevalence of the extensive UC forms at 35\% [22]. Such a finding should raise alarms about the delayed diagnosis of UC in Saudi Arabia, which could lead to worse outcomes and increased risk of intestinal surgeries [23].

Still, several limitations should be addressed. First, data about beverage consumption was collected via a self-administered questionnaire; therefore, reporting bias was likely. Second, we had no data about the subtypes of tea and coffee and whether the carbonated soft drinks were sweetened or not. Third, because of the limited number of cases per beverage consumption frequency group, we merged the groups representing non-daily beverage intake into one group. Thus, a dose-response association could not be assessed. Fourth, patients and their controls were recruited from one private polyclinic in Saudi Arabia. People who attend private clinics could have a higher socio-economic index and consequently consume more beverages, especially carbonated soft drinks, than other people who attend public clinics. Fifth, since controls were patients who had other gastrointestinal manifestations that could be related to beverage consumption, the association might be diluted. Sixth, UC patients and controls were collected over a relatively long period, during which the popular trends toward consuming beverages might have changed. Seventh, although UC patients were newly diagnosed, the high prevalence of extensive forms suggests that those patients had delayed UC diagnosis; therefore, their reports on beverage consumption might not have preceded the onset of UC.

\section{Conclusions}

This manuscript showed that UC was negatively associated with frequent coffee and tea consumption but positively associated with frequent carbonated soft drink intake. A population-based prospective cohort study is needed to confirm our findings.

Author Contributions: Conceptualization, A.A. (Anas Almofarreh); methodology, A.A. (Anas Almofarreh); software, S.H.L.; validation, A.A. (Anas Almofarreh), H.A.S., A.A. (Ahmed Arafa), S.S.A., O.A., W.A.-H., M.M.M., A.A.-H. and S.H.L.; formal analysis, A.A. (Anas Almofarreh); investigation, A.A. (Anas Almofarreh); resources, S.H.L.; data curation, A.A. (Anas Almofarreh); writing-original draft preparation, A.A. (Anas Almofarreh); writing-review and editing, A.A. (Anas Almofarreh), H.A.S., A.A. (Ahmed Arafa), S.S.A., O.A., W.A.-H., M.M.M., A.A.-H. and S.H.L.; visualization, A.A. (Anas Almofarreh), H.A.S., A.A. (Ahmed Arafa), S.S.A., O.A., W.A.-H., M.M.M., A.A.-H. and S.H.L.; supervision, S.H.L.; project administration, A.A. (Anas Almofarreh). All authors have read and agreed to the published version of the manuscript.

Funding: This research received no external funding.

Institutional Review Board Statement: The Research Ethics Committee of King Fahd Medical City approved the study protocol.

Informed Consent Statement: Informed consent was obtained from UC patients and controls before participation.

Data Availability Statement: Not applicable.

Acknowledgments: The authors are grateful to the Deanship of Scientific Research and Scientific Research Chairs' Vice Deanship in King Saud University for supporting the research financially.

Conflicts of Interest: The authors declare no conflict of interest.

\section{References}

1. Ungaro, R.; Mehandru, S.; Allen, P.B.; Peyrin-Biroulet, L.; Colombel, J.F. Ulcerative colitis. Lancet 2017, 389, 1756-1770. [CrossRef]

2. Torres, J.; Billioud, V.; Sachar, D.B.; Peyrin-Biroulet, L.; Colombel, J.-F. Ulcerative colitis as a progressive disease: The forgotten evidence. Inflamm. Bowel Dis. 2012, 18, 1356-1363. [CrossRef] [PubMed]

3. Nedelciuc, O.; Pintilie, I.; Dranga, M.; Mihai, C.; Prelipcean, C.C. Quality of life in patients with ulcerative colitis. Rev. Med. Chir. Soc. Med. Nat. Iasi 2012, 116, 756-760. [PubMed] 
4. Cohen, R.D.; Yu, A.P.; Wu, E.Q.; Xie, J.; Mulani, P.M.; Chao, J. Systematic review: The costs of ulcerative colitis in Western countries. Aliment. Pharmacol. Ther. 2010, 31, 693-707. [CrossRef]

5. Molodecky, N.A.; Soon, I.S.; Rabi, D.M.; Ghali, W.A.; Ferris, M.; Chernoff, G.; Benchimol, E.I.; Panaccione, R.; Ghosh, S.; Barkema, H.W.; et al. Increasing incidence and prevalence of the inflammatory bowel diseases with time, based on systematic review. Gastroenterology 2012, 142, 46-54. [CrossRef]

6. Nie, J.Y.; Zhao, Q. Beverage consumption and risk of ulcerative colitis: Systematic review and meta-analysis of epidemiological studies. Medicine 2017, 96, e9070. [CrossRef]

7. Boyko, E.J.; Perera, D.R.; Koepsell, T.D.; Keane, E.M.; Inui, T.S. Coffee and alcohol use and the risk of ulcerative colitis. Am. J. Gastroenterol. 1989, 84, 530-534.

8. Persson, P.G.; Ahlbom, A.; Hellers, G. Diet and inflammatory bowel disease: A case-control study. Epidemiology 1992, 3, 47-52. [CrossRef]

9. Han, M.K.; Anderson, R.; Viennois, E.; Merlin, D. Examination of food consumption in United States adults and the prevalence of inflammatory bowel disease using National Health Interview Survey 2015. PLoS ONE 2020, 15, e0232157. [CrossRef]

10. Russel, M.G.; Engels, L.G.; Muris, J.W.; Limonard, C.B.; Volovics, A.; Brummer, R.J.; Stockbrügger, R.W. Modern life' in the epidemiology of inflammatory bowel disease: A case-control study with special emphasis on nutritional factors. Eur. J. Gastroenterol. Hepatol. 1998, 10, 243-249. [CrossRef]

11. Hansen, T.S.; Jess, T.; Vind, I.; Elkjaer, M.; Nielsen, M.F.; Gamborg, M.; Munkholm, P. Environmental factors in inflammatory bowel disease: A case-control study based on a Danish inception cohort. J. Crohns Colitis 2011, 5, 577-584. [CrossRef] [PubMed]

12. Wang, Y.-F.; Ou-Yang, Q.; Xia, B.; Liu, L.-N.; Gu, F.; Zhou, K.-F.; Mei, Q.; Shi, R.-H.; Ran, Z.-H.; Wang, X.-D.; et al. Multicenter case-control study of the risk factors for ulcerative colitis in China. World J. Gastroenterol. 2013, 19, 1827-1833. [CrossRef] [PubMed]

13. Ng, S.C.; Tang, W.; Leong, R.W.; Chen, M.; Ko, Y.; Studd, C.; Niewiadomski, O.; Bell, S.; Kamm, M.A.; de Silva, H.J.; et al. Environmental risk factors in inflammatory bowel disease: A population-based case-control study in Asia-Pacific. Gut 2015, 64, 1063-1071. [CrossRef] [PubMed]

14. Fadda, M.A.; Peedikayil, M.C.; Kagevi, I.; Kahtani, K.A.; Ben, A.A.; Al, H.I.; Sohaibani, F.A.; Quaiz, M.A.; Abdulla, M.; Khan, M.Q.; et al. Inflammatory bowel disease in Saudi Arabia: A hospital-based clinical study of 312 patients. Ann. Saudi. Med. 2012, 32, 276-282. [CrossRef]

15. Al-Mofarreh, M.A.; Al-Mofleh, I.A. Emerging inflammatory bowel disease in Saudi outpatients: A report of 693 cases. Saudi. J. Gastroenterol. 2013, 19, 16-22. [CrossRef]

16. Collison, K.S.; Zaidi, M.Z.; Subhani, S.N.; Al-Rubeaan, K.; Shoukri, M.; Al-Mohanna, F.A. Sugar-sweetened carbonated beverage consumption correlates with BMI, waist circumference, and poor dietary choices in school children. BMC Public Health. 2010, 10, 234. [CrossRef]

17. Jambi, H.; Enani, S.; Malibary, M.; Bahijri, S.; Eldakhakhny, B.; Al-Ahmadi, J.; Raddadi, R.A.; Ajabnoor, G.; Boraie, A.; Tuomilehto, J. The association between dietary habits and other lifestyle indicators and dysglycemia in Saudi adults free of previous diagnosis of diabetes. Nutr. Metab. Insights 2020, 13, 1178638820965258. [CrossRef]

18. Albar, S.A.; Almaghrabi, M.A.; Bukhari, R.A.; Alghanmi, R.H.; Althaiban, M.A.; Yaghmour, K.A. Caffeine sources and consumption among Saudi adults living with diabetes and its potential effect on HbA1c. Nutrients 2021, 13, 1960. [CrossRef]

19. Lee, I.A.; Low, D.; Kamba, A.; Llado, V.; Mizoguchi, E. Oral caffeine administration ameliorates acute colitis by suppressing chitinase 3-like 1 expression in intestinal epithelial cells. J. Gastroenterol. 2014, 49, 1206-1216. [CrossRef]

20. Oz, H.S.; Chen, T.; de Villiers, W.J. Green tea polyphenols and sulfasalazine have parallel anti-inflammatory properties in colitis models. Front. Immunol. 2013, 4, 132. [CrossRef]

21. Rizzello, F.; Spisni, E.; Giovanardi, E.; Imbesi, V.; Salice, M.; Alvisi, P.; Valerii, M.C.; Gionchetti, P. Implications of the westernized diet in the onset and progression of IBD. Nutrients 2019, 11, 1033. [CrossRef] [PubMed]

22. Magro, F.; Rodrigues, A.; Vieira, A.I.; Portela, F.; Cremers, I.; Cotter, J.; Correia, L.; Duarte, M.A.; Tavares, M.L.; Lago, P.; et al Review of the disease course among adult ulcerative colitis population-based longitudinal cohorts. Inflamm. Bowel Dis. 2012, 18, 573-583. [CrossRef] [PubMed]

23. Lee, D.-W.; Koo, J.S.; Choe, J.W.; Suh, S.J.; Kim, S.Y.; Hyun, J.J.; Jung, S.W.; Jung, Y.K.; Yim, H.J.; Lee, S.W. Diagnostic delay in inflammatory bowel disease increases the risk of intestinal surgery. World J. Gastroenterol. 2017, 23, 6474-6481. [CrossRef] [PubMed] 